\title{
Dynamic Stabilization Zone Structure of Jet Diffusion Flames from Liftoff to Blowout
}

\author{
Tzong H. Chen* and Larry P. Goss $\dagger$ \\ Systems Research Laboratories, Inc., A Division of Arvin/Calspan, Dayton, Ohio 45440 \\ Douglas G. Talleył \\ University of Michigan, Ann Arbor, Michigan 48109 \\ and \\ David W. Mikolaitis§ \\ University of Florida, Gainesville, Florida 32611
}

\begin{abstract}
Structures of methane and propane jet diffusion flames under liftoff to blowout conditions are studied. The focus of this investigation is on the dynamic, time-varying features of flame propagation and stabilization near the flame base. The turbulent velocity and length scales of the flame motion were directly measured using the thin-filament pyrometry (TFP) technique at high sampling rates. A significant change in the turbulent velocity and length scales of the measured flame was observed as the jet velocity increased, approaching the blowout condition. The deduced turbulent diffusivity displayed over one order of magnitude increase from liftoff to blowout. The strain rate, however, never exceeded $\sim 6001 / \mathrm{s}$. Near blowout, the flame base became very broad.
\end{abstract}

\section{Nomenclature}

$D_{t}=$ measured turbulent diffusivity associated with flamesurface fluctuation

$f \quad=$ flame crossing frequency

$h=$ flame liftoff height, $\mathrm{mm}$

$\Delta h=$ magnitude of liftoff-height fluctuation, $\mathrm{mm}$

$L=$ length scale of flame-surface motion; root-meansquare value of radial flame location, $\mathrm{mm}$

$S_{r}=$ measured strain rate deduced from turbulent-flamesurface motion

$S_{t}=$ Strouhal number

$S_{u}=$ maximum value of laminar burning velocity

$U_{e}=$ jet exit velocity, $\mathrm{m} / \mathrm{s}$

$v^{\prime}=$ velocity scale of flame-surface motion; root-meansquare value of radial velocity, $\mathrm{m} / \mathrm{s}$

$\nu=$ kinematic viscosity

$\bar{\rho}=$ density ratio of fuel to ambient air

\section{Introduction}

$\mathbf{T}$ OPICS related to propagation and stabilization of turbulent, lifted jet diffusion flames have been widely investigated. ${ }^{1-11}$ The investigative tools used in these studies included flame visualization and point and two-dimensional measurements. Point measurements typically included determination of velocity, temperature, and species concentration as well as joint measurement of the above properties using laser Doppler velocimetry (LDV), Raman spectroscopy, coherent anti-Stokes Raman spectroscopy (CARS), LDV/Raman, and LDV/CARS. Two-dimensional measurements of the above properties were achieved through the use of techniques such as Rayleigh imaging, Raman scattering, and laserinduced fluorescence (LIF). Despite these efforts, only lim-

Presented as Paper 89-0153 at the AIAA 27th Aerospace Sciences Meeting, Reno, NV, Jan. 9-12, 1989; received April 11, 1990; revision received Aug. 1, 1991; accepted for publication Aug. 8, 1991. Copyright (c) 1989 by the American Institute of Aeronautics and Astronautics, Inc. All rights reserved.

${ }^{*}$ Senior Research Scientist. Senior Member AIAA.

$\dagger$ Chief Scientist, Optical Diagnostics. Member AIAA.

$\ddagger$ Currently, Research Physical Scientist, Phillips Laboratory, Ed wards Air Force Base, CA 93523

$\S$ Associate Professor. ited information has been obtained on the progress of the flame motion near the flame base.

Information on the time-varying properties of the lifted flame is required for an understanding of dynamic flamestabilization processes. Such information can be obtained through the use of the thin-filament pyrometry (TFP) technique recently developed by Goss et al. ${ }^{12}$ With this technique the line temperature of the hydrocarbon turbulent jet diffusion flame can be profiled - an extremely difficult, if not impossible, task using other experimental methods. The spatially and temporally resolved temperature profile obtained by TFP at a high sampling rate yields the time-dependent flame characteristics, e.g., the location of the flame and the thickness of the flame zone. From this time-dependent information, statistical flame characteristics can be derived. In an earlier study, Chen and Goss ${ }^{13}$ utilized the TFP technique to profile the temperature of turbulent jet flames at high sampling rates. In that study, the velocity and length scales associated with flame motion were derived for methane and propane flames under critical liftoff conditions. The thermal-zone thickness and the velocity and length scales were found to increase significantly after flame liftoff. However, the time scale associated with large-scale flame movement remained within a narrow range. As a result, the derived turbulent diffusivity increased with increasing jet velocity and downstream location, while the strain rate remained essentially constant. For methane and propane flames at the critical liftoff velocity, the strain rate sustained by the flame surface was measured to be $\sim 450 \mathrm{1} / \mathrm{s}$. This result was consistent with that of other researchers. 5

In the present paper lifted flames having an exit velocity greater than the critical liftoff velocity were examined. Questions of particular interest included: 1 ) how the thermal zone varies along the flame under various liftoff conditions; 2) whether the strain rate remains limited and the range of strain rate that the flame sustains when approaching blowout; and 3 ) whether the time scale of the dominant flame motion remains constant and, if so, why. In addition, attempts have been made to quantify intermittent flame-base motion.

\section{Experimental}

In these studies the fuel jet was issued from a short, tapered, 5-mm-i.d. contour nozzle having a contraction ratio of $20: 1$. 
To isolate the flame from room-air disturbances, a $25-\mathrm{cm}$ duct was used that confined the co-annular air jet having a constant exit velocity of $0.15 \mathrm{~m} / \mathrm{s}$. The experimental setup using the TFP technique to study flame lifting and flame/flow interactions of turbulent jet diffusion flames is described in detail in Refs. 12 and 13 . Therefore, only a brief description is given here.

Time-dependent temperature profiles for the propane and methane jet flames were made at a rate of $>3000 / \mathrm{s}$ from the blackbody emission of a $\sim 10-\mu$ m-diam $\mathrm{SiC}$ thin filament having a frequency response of $\sim 1000 \mathrm{~Hz}$. The spatial resolution of the current configuration was varied from 60 to $150 \mu \mathrm{m}$. The total length of the filament, $\sim 12 \mathrm{~cm}$, was sufficient to allow radial examination of the entire jet-flame zone. The curve-fitting process was applied to each temperature profile to permit accurate determination of the radial position of the flame surface and the thickness of the thermal zone. Because the data were taken at a high sampling rate, the time-varying information could be captured and recorded. From the timeseries trace of the flame surface, the radial velocity and length scales of the flame propagation could be deduced. The radial velocity is the time derivative of the flame trace; this trace is obtained by aligning the filament in the radial direction. The root-mean-square (rms) value of the radial velocity $v^{\prime}$ is defined as the velocity scale; whereas, the rms value of the radial flame location $y^{\prime}$ is defined as the length scale $L$.

The experimental conditions are summarized in Table 1. For the propane flame the heat released was very intense. As a result a high-velocity propane flame could not be operated for long periods of time in the exhaust facility. Thus, the propane flame was not tested for jet velocities $>40 \mathrm{~m} / \mathrm{s}$. For the methane flame this problem was less severe. However, for a methane flame having an exit velocity $>60 \mathrm{~m} / \mathrm{s}$, the liftoff height was $>140 \mathrm{~mm}$ and fluctuated at an amplitude $>35 \mathrm{~mm}$. In addition, the flame was no longer flamelet-like in character. Use of the fitting process for locating the flame peaks ${ }^{13}$ could not be justified in this case. Therefore, temperature profiles for the methane flames having a velocity of $70 \mathrm{~m} / \mathrm{s}$ were made, but the data were not analyzed by means of the fitting process. The flame conditions shown in Table 1 (labeled Case Nos. 1-5) were examined, and the results are presented herein. The measurement locations were chosen in the near-field region from the flame base (liftoff height) up to 40 jet diameters downstream, $x / d=40$. In this region the fuel-jet shear layer and flame surface interact strongly, allowing deformation of the flame surface to be studied.

\section{Results and Discussion}

It has been shown ${ }^{13}$ that under critical liftoff conditions, the methane diffusion flame experiences stronger flame/flow interaction than the propane flame. This was later confirmed using laser-induced $\mathrm{OH}$ fluorescence ${ }^{14}$ to study the statistical flame-zone characteristics. In the present study it was found that when the flame condition approaches blowout, the flame/ flow interaction becomes stronger for both flames. For examining the progress of the flame behavior, data are presented in the following order: 1) general flame-liftoff characteristics;

Table 1 Experimental conditions

\begin{tabular}{cclll}
\hline \hline & $\begin{array}{c}\text { Exit } \\
\text { velocity, } \\
\mathrm{m} / \mathrm{s}\end{array}$ & $\begin{array}{c}\text { Flame } \\
\text { status }\end{array}$ & \multicolumn{1}{c}{$\begin{array}{c}\text { Origin of } \\
\text { data }\end{array}$} & $\begin{array}{c}\text { Case } \\
\text { no. }\end{array}$ \\
\hline Propane & 19.5 & Attached & Ref. 13 & \\
Propane & 19.5 & Lifted & Ref. 13 & Present study \\
Propane & 29.0 & Lifted & Present study & 1 \\
Propane & 38.5 & Lifted & Ref. 13 & 2 \\
Methane & 31.0 & Attached & Ref. 13 & \\
Methane & 31.0 & Lifted & Present study & 3 \\
Methane & 40.0 & Lifted & Present study & 4 \\
Methane & 50.0 & Lifted & Present study & 5 \\
Methane & 60.0 & Lifted & Present study & 6 \\
Methane & 70.0 & Lifted & & \\
\hline \hline
\end{tabular}

2) thermal-zone thickness and velocity and length scales; 3) deduced diffusivity and strain rate; and 4) crossing frequency that behaves in a manner similar to the strain rate.

\section{A. Liftoff Height and Fluctuations}

In the study of the stabilization of lifted flames, the classical approach involves an initial examination of the liftoff height. ${ }^{15,16}$ Measurement of liftoff height has most often been accomplished by direct observation, but it can be achieved more effectively through the use of a thin filament to indicate the presence of the flame. The observed flame height fluctuates, indicating the dynamic interaction of the shear zone and the flame zone. This interaction becomes even stronger after the flame lifts and can be influenced by 1) chemical kinetics of the mixture in the fuel jet; 2) fluid properties of the fuel jet and coflowing jet; 3 ) initial flow conditions; and 4) geometry effects that may be inherent in the flow conditions. This nonsteady interaction can cause intermittent flame behavior. In the present study the range of intermittent flame-base motion is characterized by recording both the lower and upper bounds of the liftoff height along with the average height.

The average liftoff height $h$ and the difference in liftoff height between the lower and upper bounds $\Delta h$ are plotted in Figs. 1 and 2, respectively, as a function of exit velocity. The exit velocity was calculated from the volume flow rate and the nozzle diameter of $5 \mathrm{~mm}$. The exit velocity profiles are described in detail in Ref. 17. The initial liftoff condition for the methane and propane flames is indicated in Fig. 1. After the flame lifts, it jumps to an initial liftoff height. A reduction in jet velocity will decrease the liftoff height and eventually cause the flame to re-attach. This re-attaching regime in the figure is the region where the velocity is lower than the initial liftoff velocity. After initial liftoff an increase in the jet velocity will increase the liftoff height and eventually cause the flame to blow out. The blowout velocity for the methane flame is $\sim 80 \mathrm{~m} / \mathrm{s}$ and that for the propane flame is $>90 \mathrm{~m} / \mathrm{s}$.

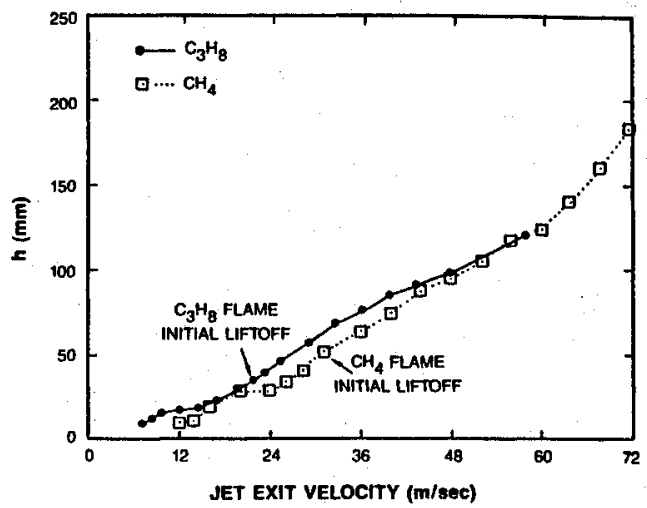

Fig. 1 Plot of average liftoff height as function of jet exit velocity.

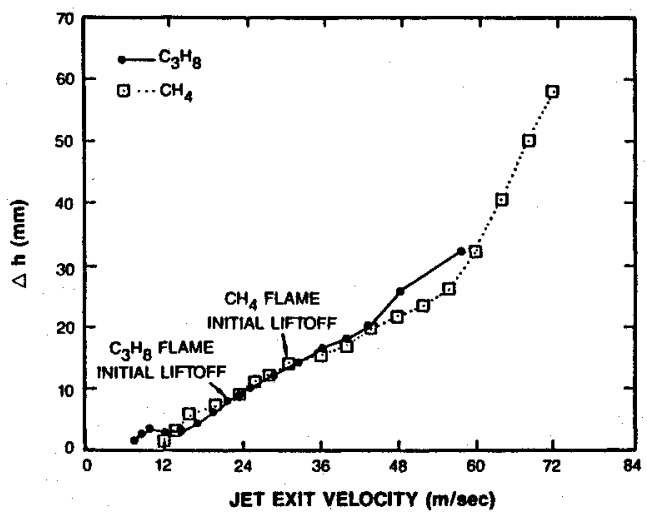

Fig. 2 Plot of amplitude of liftoff-height fluctuation as function of jet exit velocity. 
For the methane and propane flames, a linear relationship is observed between liftoff height $h$ and jet velocity $U_{e}$, which confirms the results of a previous study of Kalghatgi. ${ }^{15}$ This relation for the propane flame is given by

$$
h=-21.74+2.50 U_{e}
$$

and for the methane flame by

$$
h=-28.45+2.61 U_{e}
$$

with $h$ being in millimeters and $U_{e}$ in meters per second. Figure 1 shows that the initial liftoff height for the propane flame is $\sim 30 \mathrm{~mm}$, which is much lower than that of the methane flame, $\sim 52 \mathrm{~mm}$.

A linear relationship also exists between $U_{e}$ and $\Delta h$ for the methane and propane flames. Over the jet-velocity range $16-$ $45 \mathrm{~m} / \mathrm{s}, \Delta h$ for the two flames is nearly equal. The relation is

$$
\Delta h=-5.66+0.626 U_{e}
$$

Considering the differences in the reaction kinetics and fluid properties of methane and propane flames, the equal $\Delta h$ shown in Fig. 2 requires further investigation. Comparing $\Delta h$ to $h$ for the flames studied, $\Delta h$ was $\sim 20 \%$ of $h$ and $\sim 50 \%$ of the flame diameter, or $100 \%$ of the flame radius. The fluctuation of the flame height is mainly large scale in nature. As the blowout condition was approached, $h$ was $-200 \mathrm{~mm}$ and $\Delta h$ $\sim 60 \mathrm{~mm}$, as shown in Figs. 1 and 2, respectively.

Because coflowing air was employed, the results cannot be directly compared with those obtained by other investigators. However, for modeling-comparison purposes, one can apply the nondimensional analysis of Kalghatgi. ${ }^{15}$ For hydrocarbon gases the relationship between $h$ and $U_{e}$ was given by Kalghatgi ${ }^{15}$ as

$$
h=C_{1}\left(U_{e} \nu / S_{u}^{2}\right)(\bar{\rho})^{1.5}
$$

where $\nu$ is the kinematic viscosity, $S_{u}$ the maximum value of the laminar burning velocity, and $\bar{\rho}$ the density ratio of fuel to ambient air. $C_{1}$ in this equation is an empirical constant that is independent of the gas employed. If the fluid properties of the gases employed are known, $C_{1}$ can be obtained by comparing Eqs. (1), (2), and (4). For the case of methane and propane flames, $C_{1}$ was determined to be 59 and 61 , respectively. These two numbers are essentially equal within the experimental uncertainty of this measurement. Thus, these measurements support the universal law described in Eq. (4), with $C_{1} \approx 60$. The value of $C_{1}$ cited by Kalghatgi is 50 ; the flow conditions relative to the coflowing air and the nozzle geometry employed in the present study could account for this difference.

\section{B. Velocity Scale, Length Scale, and Thermal-Zone Thickness}

Because the turbulent flame has been viewed as an ensemble of flamelets, the radial velocity and length scales associated with turbulent flame motion and the thermal-zone thickness were measured in order to characterize the progress of the propagation and stabilization of lifted jet flames. The results are shown in Figs. 3, 4, and 5, respectively.

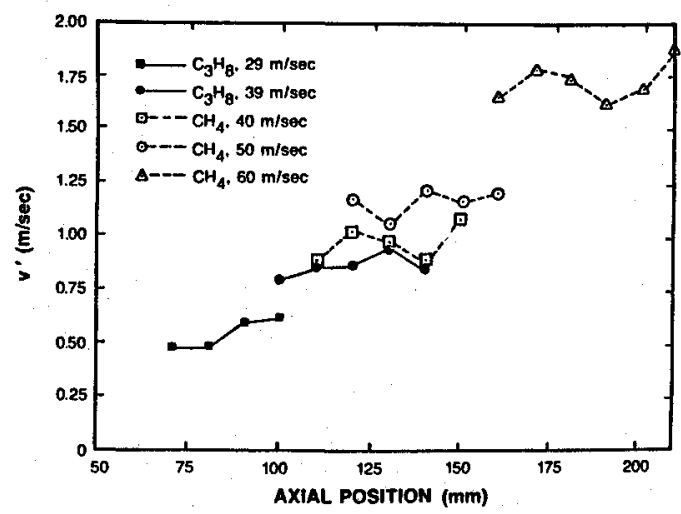

Fig. 3 Plot of measured rms value of radial velocity fluctuation as function of axial location.

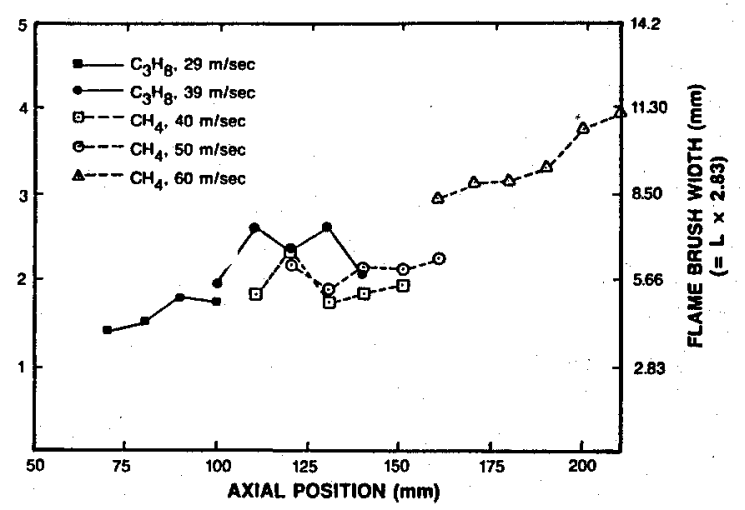

Fig. 4 Plot of measured rms value of flame fluctuation as function of axial location.

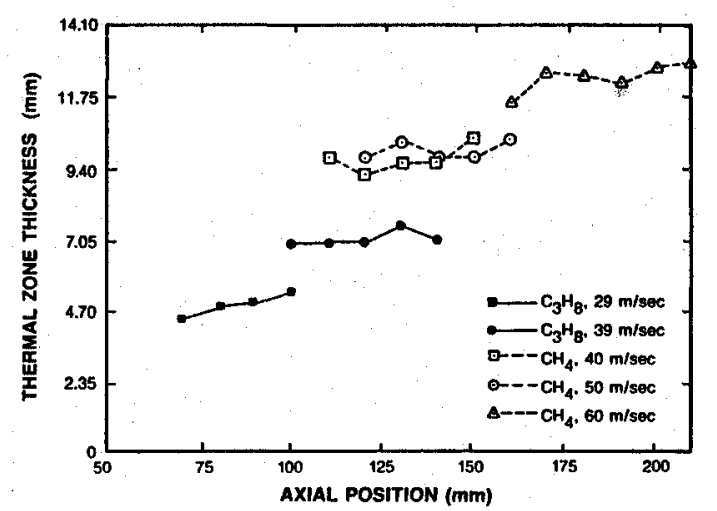

Fig. 5 Plot of thermal-zone thickness as function of axial location.

In Fig. 3 the radial velocity fluctuation $v^{\prime}$ for the motion of the flame surface is plotted as a function of axial location for the five flame conditions selected for study. With increasing jet velocity and downstream location, $v^{\prime}$ for both propane and methane flames consistently increased. The methane flame displayed a higher fluctuation than the propane flame. ${ }^{13}$ The maximum radial velocity observed was $\sim 1.8 \mathrm{~m} / \mathrm{s}$ for the lifted methane flame having a jet exit velocity of $60 \mathrm{~m} / \mathrm{s}$. The local maximum axial velocity at the measurement location was estimated to be $\sim 12 \mathrm{~m} / \mathrm{s}$. Under these circumstances the normalized velocity fluctuation was $\sim 15 \%$, which is comparable to the jet turbulent intensity. For this flame condition, the flame surface motion may be passive and dominated by the flowfield. The measured maximum turbulent velocity is approximately four to five times the maximum laminar flame velocity.

The rms value of the flame fluctuation $L$ is shown in Fig. 4. Because $L$ is an rms value, the actual range of the inner and outer bounds of the flame position should be $\sim 2.83 \mathrm{~L}$. This range is the flame-brush width and is shown on the righthand vertical axis in Fig. 4. The dependence of $L$ upon the flame conditions and axial location was similar to that of $v^{\prime}$. When the flame-brush width was normalized by the radius of the flame cone, the normalized value was found to be $\sim 20 \%$ for most of the flame conditions tested. For Test Condition No. 5 in Table 1 (the methane flame having an exit velocity of $60 \mathrm{~m} / \mathrm{s}$ ), the above normalized value approached $58 \%$.

Figure 5 is a plot of the thermal-zone thickness, which is defined as the width of the flame zone for temperatures above $\sim 1300 \mathrm{~K}$. For measurements of the reaction-zone thickness, a spectroscopic technique ${ }^{10}$ is required; such measurements were not attempted in the present study. The thermal zone should be thicker than the reaction zone because the thickness of the former is equal to the thickness of the latter plus the thermal-boundary-layer thickness. However, measurement of the thermal-zone thickness yields the size of the area confining the hot combustion products that have a temperature higher than the ignition temperature. The results in Fig. 5 clearly indicate that the methane flame has a thicker thermal zone 
than the propane flame, presumably due to the higher thermal diffusivity of methane. ${ }^{13}$

For Test Condition No. 5 (see Table 1), the observed thickness was $\sim 13 \mathrm{~mm}$. For the methane flame having a slightly higher exit velocity of $70 \mathrm{~m} / \mathrm{s}$ (very near blowout), the thermal zone became extremely thick; in this case, the entire flame cone may assume the characteristics of distributed combustion. This is demonstrated in Fig. 6 by the evolution of the temperature profile near the flame base, at a location $\sim 175$ $\mathrm{mm}$ downstream. Here it is clear that the entire flame cone is filled with hot combusting gases. The intermittent flame motion can be observed in this figure. When the flame is stabilized at a location above the filament, no signal appears; when the flame moves down toward the filament, the hightemperature zone can be observed. This transition clearly shows that under the near-blowout condition, the thermal zone is thick, even at the stabilized flame base.

\section{Turbulent Diffusivity and Strain Rate}

In the near field of the jet, the flame is perturbed by the flow turbulence, and the flame surface becomes contorted; the surface area increases accordingly, raising the consumption rate of the reactant mixture. However, the contorted flame surface is also accompanied by an increase in strain rate. If the strain rate reaches a certain value, the flame will be quenched locally. ${ }^{18}$ The strain rate sustained by the flame surface can be estimated from the length and velocity scales associated with the flame-surface motion. In this experiment, the flame motion was directly tracked by the TFP technique. The measured velocity scale $v^{\prime}$ and the length scale $L$ associated with the flame fluctuation can be used to determine the important parameters turbulent diffusivity and strain rate using the following relations:

$$
\begin{aligned}
& D_{t}=v^{\prime} L \\
& S_{r}=v^{\prime} / L
\end{aligned}
$$

The units for $D_{r}$ and $S_{r}$ are the same as those for turbulent diffusivity and strain rate, respectively. In a typical flame study when information on the direct flame-surface motion is not available, the velocity and length scales are derived from the velocity measurement of the flowfield. The velocity measured in this way, however, does not necessarily characterize the flame motion because the flame may not completely respond to the flow motion and, as a result, the turbulent Prandtl number will not be unity. Because these two quantities were measured for the first time in the present study, no comparison with previous literature was possible. Therefore, for reference purposes, the value of $D_{t}$ was referred to as turbulent diffusivity with an assumed proportional constant of unity. The same convention was applied to the value of $S_{r}$, which was referred to as strain rate.

Figures 7 and 8 show turbulent-diffusivity and strain-rate results, respectively. Under high jet-velocity conditions, the flame base could not be characterized as an ideal flamelet for either the methane or the propane flame. The probability of observing multiple flamelets and thick flame zones increased with increasing jet velocity, an observation which was con-

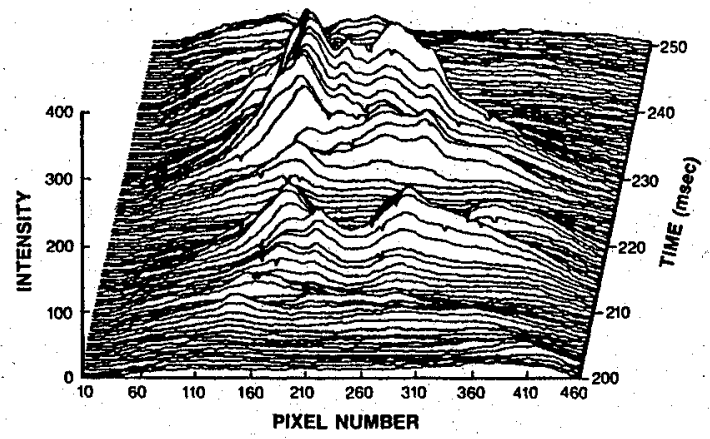

Fig. 6 Three-dimensional plot of TFP results for methane flame base at $70 \mathrm{~m} / \mathrm{s}$.

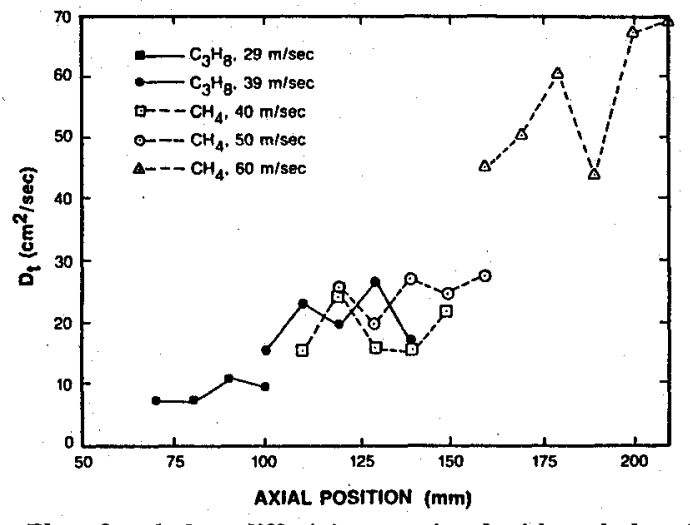

Fig. 7 Plot of turbulent diffusivity associated with turbulent-flamesurface motion as function of axial location.

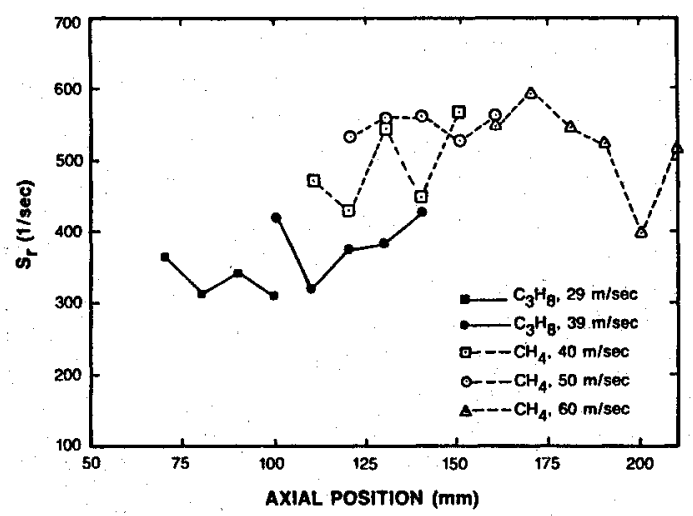

Fig. 8 Measured strain rate deduced from turbulent-flame-surface motion.

firmed in a later experimental study. ${ }^{14}$ This nonflamelet behavior reduced the success rate of curve fitting and, thus, the quality of the data. For the methane flame the quality of the data was lower than for the propane flame. Furthermore, the total number of profiles sampled at each location was only 720. Under-sampling constitutes a special problem for diffusivity and strain-rate calculations that are composed of two measured quantities; therefore, the data presented should not be considered benchmark results. Instead, attention should be focused on the trend and range of the results.

At the critical liftoff velocity, the turbulent diffusivity at the liftoff height for the propane flame is $\sim 2 \mathrm{~cm}^{2} / \mathrm{s}$ and for the methane flame is $\sim 10 \mathrm{~cm}^{2} / \mathrm{s}$. Figure 7 shows that turbulent diffusivity increased with an increase in jet velocity and downstream location. However, the strain rate sustained by the flame surface remained relatively constant, as shown in Fig. 8. For the propane flame, the strain rate for the lifted flame remained at $\sim 3501 / \mathrm{s}$, which is lower than that for the attached flame at the critical liftoff velocity. For the methane flame the strain rate for the lifted flame remained at $\sim 5401 / \mathrm{s}$, which is higher than that for the attached flame at the critical liftoff velocity. It seems that the flame sustains a certain strain rate over a wide range of flame conditions. Note that the strain rate was deduced from the statistical quantities, as shown in Eq. (6). The instantaneous strain rate sustained by the flame may be different. However, a later study by Seaba ${ }^{17}$ indicated that this deduced strain rate is very similar to the result obtained by mean-flow-velocity measurements made around the flame base.

\section{Crossing Frequency of Flame Surface}

As reported in a companion study, ${ }^{13}$ the flame can influence the flowfield and be influenced by it. This is evident from data on the crossing frequency, which is defined as the frequency at which the flamefront crosses its mean position. Before reaching the end of the potential core, the jet-shearlayer structure becomes larger after the flame lifts and, consequently, the flame-crossing frequency decreases after the 


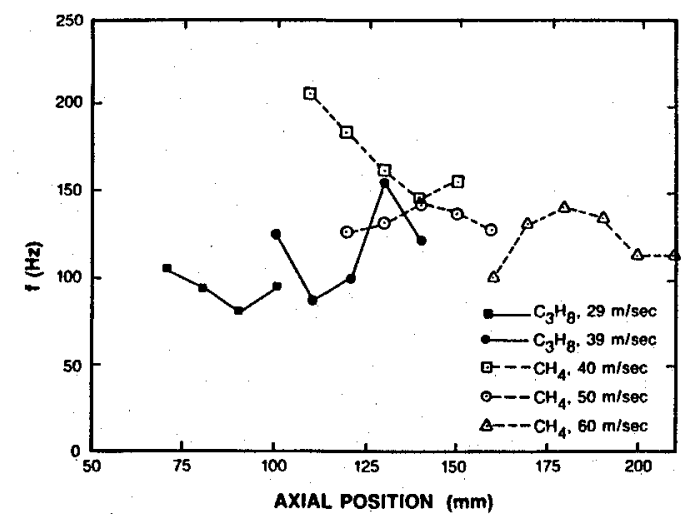

Fig. 9 Measured crossing frequency of flame surface at different downstream locations.

flame has lifted. For the methane flame the interaction is strong and the structure less coherent; as a result the frequency decreases irregularly. However, the frequency of the lifted methane flame falls between 100 and $150 \mathrm{~Hz}$. For the propane flame in which the interaction of the shear zone and the flame zone is weaker, the frequency decreases by onehalf from 200 to $100 \mathrm{~Hz} .{ }^{13}$ Under the flame conditions selected for this study, which range from liftoff to blowout, this trend was observed and the measured frequency remained in the $100-150 \mathrm{~Hz}$ range, as shown in Fig. 9.

The exact reason for the crossing frequency of the methane and propane flames falling into the range $\sim 100-150 \mathrm{~Hz}$ over a wide exit-velocity region is not clear. Nevertheless, this indicates the dominant time scale over which the lifted flame responds to flow modulation. Because the region between the lifted flame base and the nozzle mouth is a preferred location for entrainment of air, ${ }^{13}$ it is physically sound to assume that the liftoff height is an important length scale that affects flame behavior. Variation of liftoff height may, in turn, affect air entrainment, local fuel-air mixing, and, thus, flame stabilization. To quantify the consequence of this unsteady flame/ flow coupling, a nondimensional ratio equivalent to the Strouhal number $S_{t}$ can be defined as

$$
S_{t}=f h / U_{e}
$$

where $f$ is the dominant frequency. In the above definition, global parameters such as $h$ and $U_{e}$ are used. From the data in Figs. 1 and 9, the Strouhal number is found to range from $\sim 0.10$ to 0.15 . Note that over a wide range of flame conditions, the ratio $h / U_{e}$ remains constant, as shown in Fig. 1 . Thus, if the Strouhal number defined in Eq. (7) for characterizing the unsteady flame/flow coupling is to be constant, then the frequency $f$ must be constant, as shown in Fig. 9.

\section{Conclusions}

A novel approach was taken to the characterization of the stabilization-zone structure of jet flames. Methane and propane flames having an exit velocity ranging from liftoff to near blowout were examined and the results compared. Emphasis in this study was placed on the measurement of timevarying properties in order to characterize the dynamic behavior related to flame propagation and stabilization. The results are summarized below.

1) In the near-field region of the lifted flame, the thermalzone thickness and the velocity and length scales associated with the flame motion increased with respect to an increase in the jet velocity and downstream distance. Under the same jet-velocity conditions, the methane flame fluctuated at higher velocity and amplitude than the propane flame.

2) The strain rate sustained by the flame remained relatively constant for the wide range of flame conditions tested.

3) The intermittent behavior of the flame-stabilization zone was characterized. The fluctuation of the liftoff height was measured to be $\sim 20 \%$ of the average value.
4) Unsteady flame/flow coupling resulted in a Strouhal number ranging from $\sim 0.10$ to 0.15 . The liftoff height is considered to be an important physical length scale.

5) Approaching the near-blowout condition, the flame base fluctuated violently and the flame may take on distributedcombustion characteristics.

\section{Acknowledgments}

This work was supported in part by the Aero Propulsion and Power Directorate, Wright Laboratory, Wright-Patterson Air Force Base, under Contract F33615-85-C-2562. The authors are indebted to W. M. Roquemore for helpful discussions and support of this work and to M. Whitaker, D. D. Trump, V. Vilimpoc, and B. Sarka for technical assistance.

\section{References}

'Vanquickenborne, L., and van Tiggelen, A., "The Stabilization Mechanism of Lifted Diffusion Flames," Combustion and Flame, Vol. 10, No. 3, 1966, pp. 59-69

${ }^{2}$ Eickhoff, H., Lenze, B., and Leuckel, W., "Experimental Investigation on the Stabilization Mechanism of Jet Diffusion Flames," Twentieth Symposium (International) on Combustion, The Combustion Institute, Pittsburgh, PA, 1985, pp. 311-318.

${ }^{3}$ Roquemore, W. M., Chen, L. D., Goss, L. P., and Lynn, W. F., "Structure of Jet Diffusion Flames," Turbulent Reactive Flows (Lecture Notes in Engineering), edited by R. Borghi and N. B. Murthy, Vol. 40, Springer-Verlag, New York, 1989, pp. 49-63.

${ }^{4}$ Peters, N., and Williams, F. A., "Liftoff Characteristics of Turbulent Jet Diffusion Flames," AIAA Journal, Vol. 21, No. 3, 1983 pp. $423-429$.

"Bilger, R. W., "Turbulent Diffusion Flames," Annual Review of Fluid Mechanics, Annual Reviews Inc., Palo Alto, CA, 1989, Vol. 21, pp. 101-135.

${ }^{6}$ Broadwell, J. E., and Breidenthal, R. E., "A Simple Model of Mixing and Chemical Reaction in a Turbulent Shear Layer," Journal of Fluid Mechanics, Vol. 125, No. 12, 1982, pp. 397-410.

${ }^{7}$ Dahm, W. J. A., and Dibble, R. W., "Combustion Stability Limits of Coflowing Turbulent Jet Diffusion Flames," AIAA Paper 88-0538, Reno, NV, 1988.

${ }^{8}$ Haworth, D. C., Drake, M. C., Pope, S. B., and Blint, R. J., "The Importance of Time-Dependent Flame Structures in Stretched Laminar Flamelet Models for Turbulent Jet Diffusion Flames," TwentySecond Symposium (International) on Combustion, The Combustion Institute, Pittsburgh, PA, 1989, pp. 589-597.

${ }^{9}$ Masri, A. R., Starner, S. H., and Bilger, R. W., "Transition and Transport in the Initial Region of a Turbulent Diffusion Flame," Dynamics of Flames and Reactive Systems, edited by J. R. Bowen, N. Manson, A. K. Oppenheim, and R. I. Soloukhin, Vol. 95, Progress in Astronautics and Aeronautics, AIAA, Washington, DC, 1984, pp 293-304.

${ }^{10}$ Schefer, R. W., Namazian, M., and Kelly, J., "Structural Characteristics of Lifted Turbulent-Jet Flames," Twenty-Second Symposium (International) on Combustion, The Combustion Institute, Pittsburgh, PA, 1988, pp. 833-842.

${ }^{11}$ Takahashi, F., Mizomoto, M., and Ikai, S., "Structure of the Stabilizing Region of a Laminar Jet Diffusion Flame," Journal of Heat Transfer, Vol. 110, No. 2, 1988, pp. 182-189.

${ }^{12}$ Goss, L. P., Vilimpoc, V., Sarka, B., and Lynn, W. F., "ThinFilament Pyrometry: A Novel Thermometric Technique for Combusting Flows," Journal of Engineering for Gas Turbines and Power, Vol. 111, 1989, pp. 46-52.

${ }^{13}$ Chen, T. H., and Goss, L. P., "Flame Lifting and Flame/Flow Interactions of Jet Diffusion Flames," AIAA Paper 89-0156, Reno, NV, Jan. 1989.

${ }^{14}$ Chen, T. H., and Goss, L. P., "Statistical OH-Zone Structures of Turbulent Jet Flames from Liftoff to Near-Blowout," Combustion Science and Technology, Vol. 79, 1991, pp. 311-324.

${ }^{15}$ Kalghatgi, G. T., "Lift-off Heights and Visible Lengths of Vertical Turbulent Jet Diffusion Flames in Still Air," Combustion Science and Technology, Vol. 41, 1984, pp. 17-29.

${ }^{16}$ Pitts, W. M., "Assessment of Theories for the Behavior and Blowout of Lifted Turbulent Jet Diffusion Flames," Twenty-Second Symposium (International) on Combustion, The Combustion Institute, Pittsburgh, PA, 1988, pp. 809-816.

${ }^{17}$ Seaba, J. P., "Burner Statistics of Jet Diffusion Flames," Ph.D. Dissertation, Univ. of Iowa, Iowa City, IA, 1990.

${ }^{18}$ Lewis, B., and von Elbe, B., Combustion, Flames and Explosions of Gases, 3rd ed., Academic Press, New York, 1987. 